\title{
Ohio Community Pharmacist Provision of Clinical Preventive Services
}

\author{
Scott Alexander, PharmD Candidate; Natalie DiPietro Mager, PharmD, MPH
}

Ohio Northern University Raabe College of Pharmacy

\begin{abstract}
Objective: The primary objective of this study was to assess whether Ohio community pharmacists currently provide certain evidencebased clinical preventive services. Secondary objectives were to explore whether there were any differences in provision of services based on respondent education, position, employment status, location, practice setting, or years in practice and to gather information on how pharmacists provide specific services, barriers to providing specific services, pharmacists' perceptions on specific services needed in their patient population, and pharmacists' interests in providing services if not already doing so.

Methods: A random sample of 500 community pharmacists licensed in Ohio received a Qualtrics survey via email assessing current practices and perspectives regarding clinical preventive services. The U.S. Preventive Services Task Force (USPSTF) " $A$ " and " $B$ " recommended services that can be provided in a community pharmacy served as the framework for the survey questions. Reminders were sent every 3-4 days; data collection continued for a month. The study was IRB-approved.

Results: Ninety-three responses were included in the final analysis (18.9\% response rate). Approximately 63\% of respondents were female; $51.6 \%$ held a Doctor of Pharmacy degree. Only $21.5 \%$ of respondents were familiar with the USPSTF. However, many respondents were providing clinical preventive services in their pharmacy; the most common were blood pressure screening (51.6\%), tobacco use screening or counseling (43\%), and diet and/or physical activity counseling (22.6\%). These services were provided in varied ways including patient counseling, medication therapy management sessions, screening events, and health fairs. Those who are not currently providing services showed interest in developing them. Pharmacists reported barriers such as lack of time, staff, and reimbursement by patients or third-party payers.

Conclusion: Many surveyed community pharmacists in Ohio reported providing clinical preventive services in a variety of ways. Many pharmacists who did not provide these services indicated an interest developing such services. Staffing concerns, time constraints, and a lack of reimbursement by patients and third-party payers were reported as barriers by community pharmacists in providing these services. As many respondents reported being unfamiliar with USPSTF recommendations, the opportunity to educate pharmacist on these recommendations and potentially increase their activity in these prevention activities exists.
\end{abstract}

Keywords: clinical preventive services, U.S. Preventive Services Task Force, pharmacists, community pharmacy

\section{Introduction}

Clinical preventive services such as immunizations and routine disease screenings can decrease morbidity and mortality ${ }^{1}$. However, many adults in the United States (U.S.) do not receive necessary clinical preventive services. ${ }^{1,2}$ A recent study showed that as of 2015, only $8 \%$ of adults in the U.S. 35 years and older had received all recommended clinical preventive services. Close to $5 \%$ of U.S. adults did not receive any of the clinical preventive services recommended for them. ${ }^{2}$

Community pharmacists have the knowledge and training to provide many clinical preventive services. ${ }^{3.4}$ The pharmacists' advanced education and continuing professional development allows them to disseminate basic health advice to patients in the form of counseling. In addition, the community pharmacist often has access to tools and equipment to facilitate screening and monitoring for various disease states such as hypertension or Type 2 diabetes.

Corresponding author: Natalie DiPietro Mager, PharmD, MPH Ohio Northern University Raabe College of Pharmacy

Email: n-dipietro@onu.edu
The accessibility of the community pharmacist also provides opportunities for delivery of these services to the public. Most community pharmacists meet with patients without an appointment, and many pharmacies are open extended hours. It has been estimated that one-third to one-half of U.S. residents do not have a medical home; however, the average resident lives within 5 miles of a community pharmacy. ${ }^{5}$ In addition, vulnerable or hard-to-reach populations are often able to access a community pharmacy. ${ }^{6}$ Due to their availability and expertise, there is great potential for community pharmacists to provide clinical preventive services and close gaps in care. . $^{3,4}$

\section{Objectives}

The primary objective of this study was to assess whether Ohio community pharmacists currently provide certain evidencebased clinical preventive services. Secondary objectives were to explore whether there were any differences in provision of services based on respondent education, position, employment status, location, practice setting, or years in practice and to gather information on how pharmacists provide specific services, barriers to providing specific services, pharmacists' perceptions on specific services needed in their 
patient population, and pharmacists' interests in providing services if not already doing so.

\section{Methods}

\section{Setting and sample}

The State of Ohio Board of Pharmacy was contacted to obtain a list of all pharmacists currently registered in Ohio as of October 2017. The list was narrowed to pharmacists with an e-mail address on-file who reported a community pharmacy in Ohio as their primary practice site. A random number generator was used to select 500 pharmacists from this list to receive the survey.

\section{Survey development and implementation}

A survey tool was developed to assess pharmacist provision of certain clinical preventive services. To identify which services to include in the survey questions, the United States Preventive Service Task Force (USPSTF) " $A$ " and " $B$ " recommended services for the general, non-pregnant adult population were utilized as a framework. The USPSTF is a group of experts utilizing evidence-based medicine to make recommendations about clinical preventive services, excluding immunizations, that should be offered in primary care settings to different patient populations (general adult, pregnant women, or pediatric). ${ }^{7}$ The USPSTF grades the varied primary or secondary prevention services as "A-I" based on the available data regarding effectiveness, benefits, and harms. The USPSTF recommendations that are classified as " $A$ " (high certainty of benefit) or " $B$ " (high certainty of moderate benefit or moderate certainty that the benefit is moderate to substantial) should be routinely provided to all individuals within the defined patient population. The USPSTF does not make specific recommendations regarding vaccinations but instead defers to the Centers for Disease Control and Prevention's (CDC) Advisory Committee on Immunization Practices (ACIP). ${ }^{7} \quad$ Previous papers have highlighted which USPSTF " $A$ " and " $B$ " recommended services pharmacists may be especially suited to provide, ${ }^{3,4}$ and the list (Table 1 ) was limited to exclude a service that would require prescription of a medication (e.g., statin preventive medication) as it would be too difficult to capture via the survey tool whether the pharmacist initiated the service or simply dispensed the medication.

Twenty-six questions were included in the survey tool. Thirteen questions captured respondent demographics, six questions assessed pharmacists' provision of clinical preventive services, and seven questions captured opinions about the services. The questions were distributed electronically via Qualtrics Labs (Provo, UT).

Six pharmacists with experience in community pharmacy pilottested the survey to assess face validity and check for any technical difficulties. The six pharmacists were not part of the sample. Following completion of pilot testing, the survey was sent via email to the sample in November 2017. Reminder emails were sent every 3-4 days; data collection continued for one month. The surveys were completed anonymously, and no incentives were offered for survey participation. The cover letter accompanying the survey did not explicitly state the focus of the survey questions. The study was approved by the Ohio Northern University Institutional Review Board.

\section{Statistical analysis}

Descriptive statistics were analyzed with Microsoft Office Excel 2013 (Redmond, WA) and analytic statistics were analyzed with IBM SPSS 22 (Armonk, NY) and Vassarstats (Poughkeepsie, NY). Chi-square or Fisher exact nonparametric statistical tests were used as appropriate to identify whether there were any significant differences in provision of clinical preventive services based on respondent education, position, employment status, location, practice setting, or years in practice. Statistical significance was defined a priori as a $p$ value of $<0.05$.

\section{Results}

The survey was delivered to 491 pharmacists ( 9 emails were undeliverable). Ninety-three pharmacists completed the survey for a response rate of $18.9 \%$. Table 2 displays the characteristics of the respondents.

Sixty-five respondents (69.9\%) reported providing at least one clinical preventive service in the community pharmacy (Table 3 ). Of the 18 services community pharmacists may be able to provide, pharmacists reported $0-12$ services provided at their location. The most common services provided were blood pressure screening (51.6\%), tobacco use screening or counseling (43\%), and diet and/or physical activity counseling (22.6\%). Ways in which pharmacists reported providing these services included individual patient counseling (36.6\%); medication therapy management (MTM) sessions (34.4\%); general education (posters in pharmacy, brochures, flyers, and other types of patient education materials) (33.3\%); screening events (24.7\%); health fairs (17.2\%); stand-alone equipment in the pharmacy (i.e., blood pressure monitors) (5.4\%); collaborative practice agreements (5.4\%); and employer contracts $(1.1 \%)$. Those who are not currently providing clinical preventive services showed interest in developing such services (Table 4).

Years in practice was statistically significantly associated with provision of at least 1 clinical preventive service $(p=0.011)$, with pharmacists who more recently entered the profession reporting that they provided more services. In addition, pharmacists who worked full-time were statistically significantly more likely to provide at least 1 service $(p<0.001)$. Education, position, location, or practice setting were not associated with provision of services.

When asked to identify the top five needs in their patient population from the list of clinical preventive services, community pharmacists selected type 2 diabetes screening 
(81.7\%), blood pressure screening (66.7\%), tobacco use screening or counseling (63.4\%), cholesterol screening (43\%), and diet/physical activity counseling (37\%). The top five needs did not change based upon whether the pharmacist was in a rural, urban, or suburban location.

Table 5 lists the barriers pharmacists reported to providing these services. The most common barriers were lack of time (79.6\%), staff (65.6\%), and reimbursement by patients or thirdparty payers $(55.9 \%)$. Of note, only $4 \%$ thought that the services were not needed in their patient populations.

Eighty-five percent of respondents indicated wanting to learn more about at least one of the services discussed in the survey (Table 6). When asked about preferred methods to receive this information, respondents most often selected web-based continuing education program $(61.3 \%)$, followed by live continuing education program (33.3\%), pharmacy journal (16.1\%), and pharmacy conference (15.1\%).

\section{Discussion}

Many stakeholders in the U.S. healthcare system are increasing their focus on preventive and primary care services. Community pharmacists in particular have great opportunity to improve patient outcomes through provision of clinical preventive services due to their accessible nature. ${ }^{8}$ The role of the community pharmacist has expanded to include comprehensive clinical services; ${ }^{9}$ over the last decade, pharmacists have reported spending more time on preventive care services such as immunizations and screenings and less time on medication dispensing. ${ }^{10}$ Pharmacists can also provide referrals for services not typically provided in a community pharmacy (e.g., cancer screenings). ${ }^{3,4}$

This study found that nearly $70 \%$ of respondents provided at least one clinical preventive service. Previously published articles have detailed the experience of an ambulatory care pharmacist providing USPSTF recommendations to employees at part of a worksite wellness program ${ }^{11}$ and systematic reviews have examined community pharmacists' provision of patient care services, including screening services. ${ }^{9,12,13}$ The findings of this study were consistent with the articles included in the systematic reviews. For example, the ways in which community pharmacists provided the screening service (walkin, health fair, counseling session) and the types of services provided (screenings for disease such as diabetes or cardiovascular disease) were similar. ${ }^{12,13}$ This survey assessed some topics not included in previous studies, such as behavioral counseling for skin cancer prevention.

Three services (intimate partner violence screening, tuberculosis screening, and osteoporosis screening) were not reported as offered by any respondent. It was surprising that no respondents reported that they conducted osteoporosis screenings, as this is a service that has been included in the published literature as occurring in community pharmacies in the U.S. ${ }^{13}$ In previous studies, pharmacists in Ohio have reported lack of training regarding intimate partner violence screening. ${ }^{14}$ Currently, tuberculosis screening is not a service routinely offered in Ohio community pharmacies.

While the USPSTF " $A$ " and " $B$ " recommendations served as a framework to determine which clinical preventive services community pharmacists should be routinely offering to patients and therefore queried in the survey, whether pharmacists were following the recommendation was not assessed. As close to $79 \%$ of respondents reported being unfamiliar with USPSTF recommendations, it may be likely that community pharmacists are providing services but may not be following evidence-based practice in regards to identification of patients most likely to benefit from the service or appropriate screening intervals. Therefore, there is a need to educate community pharmacists on the USPSTF recommendations through continuing pharmacy education. Additionally, pharmacists should be made aware of tools, such as the Electronic Preventive Services Selector, or ePSS, that can be utilized to identify which services each patient needs. ${ }^{15}$ As $85 \%$ of respondents indicated through the survey that they wanted more information about the services, it seems pharmacists would be interested in such educational opportunities. Educating community pharmacists on these recommendations could result in an increased recognition of the need and the desire to provide these services.

Furthermore, many of those who currently did not provide services were interested in developing them. Addressing the reported barriers, including reimbursement for community pharmacists to provide these services, will be essential in establishing new services and increasing capacity to impact their communities' health. Given the pharmacies' extended hours and locations in rural areas that may otherwise lack primary care services, the development of these services can have important implications for improving population health.

Limitations of this study include the response rate and possible response bias. Results may not be generalizable to all Ohio community pharmacists or community pharmacists in other states. The pharmacists' scope of practice varies by state, and this could influence which services are routinely offered by pharmacists. While the cover letter accompanying the survey did not disclose the specific focus of the study, it is possible that those responding to the survey may have differed systemically than those who did not respond to the survey. In addition, the survey tool utilized in the study was not a validated tool.

There are several potential areas for future research. This study focused on whether the pharmacist provided a particular service, but not to the level of detail of whether the services were being provided to patients as specified in the USPSTF recommendations; this is an area for further research. Future studies should also examine how many patients who 
receive these services follow-up as needed. Additional studies to determine best practices for community pharmacists to identify patients in their population most likely to benefit from these services should be performed. Studies are also needed to determine how to integrate pharmacy-based services with services provided by other healthcare providers; incorporating community pharmacists into health information exchange may help to reduce the number of duplicative services and increase communication among all members of the healthcare team. Effectiveness and cost-effectiveness of performing these services in community pharmacies compared to other settings should also be explored. Finally, patient satisfaction and receptivity to such services being provided in the community pharmacy should be studied. . $^{8,9,12,13}$

\section{Conclusion}

Many surveyed community pharmacists in Ohio reported providing clinical preventive services in a variety of ways. Many pharmacists who did not provide these services indicated an interest developing such services. Staffing concerns, time constraints, and a lack of reimbursement by patients and thirdparty payers were reported by community pharmacists as barriers in providing these services. As many respondents reported being unfamiliar with USPSTF recommendations, the opportunity to educate pharmacists on these recommendations and potentially increase their activity in these prevention activities exists. Additional studies are needed to quantify the impact of community pharmacist provision of clinical preventive services on patient outcomes.

Acknowledgements: None

Conflicts of interest: None

Funding/support: None

\section{References}

1. Healthy People 2020. Clinical preventive services. Accessed May1, 2018 from https://www.healthypeople.gov/2020/leadinghealth-indicators/2020-Ihi-topics/Clinical-PreventiveServices

2. Borsky A, Zhan C, Miller T, Ngo-Metzger Q, Bierman AS, Meyers D. Few Americans receive all highpriority, appropriate clinical preventive services. Health Aff (Millwood). 2018;37(6):925-928.

3. Kelling SE, Rondon-Begazo A, DiPietro Mager NA, Murphy BL, Bright DR. The provision of clinical preventive services by community pharmacists. Prev Chronic Dis. 2016;13:E149
4. DiPietro Mager NA, Bright DR, Murphy BL, RondonBegazo A, Kelling SE. Opportunities for pharmacists and student pharmacists to provide clinical preventive services. Innov Pharm. 2017;8(1): Article 11

5. DeArment A. Pharmacists are face of health care in community. Drug Store News. 2012;3:4e5

6. National Association of County and City Health Officials. Local health department and pharmacy partnerships for enhancing medication dispensing during emergencies. Accessed May 1, 2018 from https://www.naccho.org/uploads/downloadableresources/Programs/14-03-LHD-Pharmacypartnerships-for-emergency-response.pdf

7. United States Preventive Services Task Force. Accessed May 1, 2018 from https://www.uspreventiveservicestaskforce.org/

8. Alavere Health. Exploring pharmacists' role in a changing healthcare environment. Accessed May 1, 2018 from

https://www.nacds.org/pdfs/comm/2014/pharmacis t-role.pdf

9. Blalock SJ, Roberts AW, Lauffenburger JC, Thompson T, O'Connor SK. The effect of community pharmacybased interventions on patient health outcomes: $A$ systematic review. MCRR. 2013;70(3):235-266.

10. Gaither CA, Schommer JC, Doucette WR, Kreling DH, Mott DA. 2014 National pharmacist workforce survey. Accessed May 1, 2018 from https://www.aacp.org/article/2014-nationalpharmacist-workforce-study

11. Murphy BL, Rush MJ, Kier KL. Design and implementation of a pharmacist-directed preventive care program. Am J Health Syst Pharm. 2012;69(17):1513-8.

12. Willis A, Rivers P, Gray LJ, Davies M, Khunti K. The effectiveness of screening for diabetes and cardiovascular disease risk factors in a community pharmacy setting. PLoS One. 2014;9(4):e91157.

13. Ayorinde AA, Porteous T, Sharma P. Screening for major diseases in community pharmacies: A systematic review. Int J Pharm Pract. 2013;21(6):349-61.

14. Hilverding AT, DiPietro Mager NA Pharmacists' attitudes regarding provision of sexual and reproductive health services. J Am Pharm Assoc (2003). 2017;57(4):493-497.

15. Electronic Preventive Services Selector (ePSS). Accessed May 1, 2018 from https://epss.ahrq.gov/PDA/index.jsp 
Table 1. Clinical preventive services that community pharmacists may be able to provide ${ }^{3,4}$

\begin{tabular}{|l|}
\hline Alcohol misuse screening and counseling \\
\hline Blood pressure screening \\
\hline Breastfeeding counseling \\
\hline Cholesterol screening \\
\hline Depression screening \\
\hline Diabetes screening \\
\hline Fall prevention in older adults \\
\hline Counseling on folic acid supplementation to prevent birth defects \\
\hline Healthy diet and physical activity counseling \\
\hline Hepatitis C screening \\
\hline HIV screening \\
\hline Intimate partner violence screening \\
\hline Obesity screening and management \\
\hline Osteoporosis screening \\
\hline Sexually transmitted infection behavioral counseling \\
\hline Skin cancer behavior counseling \\
\hline Tobacco use counseling and interventions \\
\hline Tuberculosis screening \\
\hline
\end{tabular}


Table 2. Characteristics of survey respondents $(n=93)$

\begin{tabular}{|c|c|}
\hline Characteristic & n (\%) \\
\hline $\begin{array}{l}\text { Gender } \\
\text { Male } \\
\text { Female } \\
\text { Prefer not to answer }\end{array}$ & $\begin{array}{c}33(35.5) \\
59(63.4) \\
1(1.1)\end{array}$ \\
\hline $\begin{array}{l}\text { Education* } \\
\text { Bachelor of Science in Pharmacy } \\
\text { Doctor of Pharmacy } \\
\text { Residency }\end{array}$ & $\begin{array}{c}50(53.8) \\
48(51.6) \\
2(2.2)\end{array}$ \\
\hline $\begin{array}{l}\text { Years in Practice } \\
5 \text { years or less } \\
6-10 \text { years } \\
11-20 \text { years } \\
\text { More than } 20 \text { years }\end{array}$ & $\begin{array}{l}25(26.9) \\
19(20.4) \\
13(14) \\
36(38.7)\end{array}$ \\
\hline $\begin{array}{l}\text { Position* } \\
\text { Staff pharmacist } \\
\text { Pharmacy manager } \\
\text { Clinical/MTM pharmacist }\end{array}$ & $\begin{array}{l}52(55.9) \\
42(45.2) \\
11(11.8)\end{array}$ \\
\hline $\begin{array}{l}\text { Employment status } \\
\text { Full-time } \\
\text { Part-time }\end{array}$ & $\begin{array}{l}82(88.2) \\
11(11.8)\end{array}$ \\
\hline $\begin{array}{l}\text { Location } \\
\text { Rural } \\
\text { Suburban } \\
\text { Urban }\end{array}$ & $\begin{array}{l}23(24.7) \\
44(47.3) \\
26(28)\end{array}$ \\
\hline $\begin{array}{l}\text { Practice Setting } \\
\text { Chain pharmacy (e.g., CVS, Walgreens, etc) } \\
\text { Grocery (e.g., Kroger, Giant Eagle, etc) } \\
\text { Mass merchandiser (ex: Walmart, Kmart, etc) } \\
\text { Independent pharmacy } \\
\text { Blank }\end{array}$ & $\begin{array}{l}39(41.9) \\
26(28) \\
10(10.8) \\
16(17.2) \\
2(2.2) \\
\end{array}$ \\
\hline $\begin{array}{l}\text { Familiar with USPSTF recommendations } \\
\text { Yes } \\
\text { No }\end{array}$ & $\begin{array}{l}20(21.5) \\
73(78.5)\end{array}$ \\
\hline
\end{tabular}

* Respondents could select $>1$ choice 
Table 3. Respondents ( $n=93$ ) offering clinical preventive services in the community pharmacy

\begin{tabular}{|l|c|}
\hline \multicolumn{1}{|c|}{ Clinical Preventive Service } & $\mathbf{n ~ ( \% )}$ \\
\hline Alcohol misuse screening or counseling & $4(4.3)$ \\
\hline Blood pressure screening & $48(51.6)$ \\
\hline Breastfeeding counseling & $1(1.1)$ \\
\hline Cholesterol screening & $16(17.2)$ \\
\hline Depression screening & $2(2.2)$ \\
\hline Diabetes screening & $19(20.4)$ \\
\hline Fall prevention in older adults & $13(14)$ \\
\hline Counseling on folic acid supplementation to prevent birth defects & $19(20.4)$ \\
\hline Healthy diet and/or physical activity counseling & $21(22.6)$ \\
\hline Hepatitis C screening & $2(2.2)$ \\
\hline HIV screening & $2(2.2)$ \\
\hline Intimate partner violence screening & $0(0)$ \\
\hline Obesity screening and management & $7(7.5)$ \\
\hline Osteoporosis screening & $0(0)$ \\
\hline Sexually transmitted infection behavioral counseling & $5(5.4)$ \\
\hline Skin cancer behavior counseling & $9(9.7)$ \\
\hline Tobacco use screening or counseling & $40(43)$ \\
\hline Tuberculosis screening & $0(0)$ \\
\hline
\end{tabular}

* Note: Respondents could select $>1$ service

Table 4. Respondents ( $n=93$ ) not currently offering clinical preventive services in the community pharmacy but interested in doing so

\begin{tabular}{|l|l|}
\hline \multicolumn{1}{|c|}{ Clinical Preventive Service } & \multicolumn{1}{|c|}{$\mathbf{n ( \% )}$} \\
\hline Alcohol misuse screening or counseling & $37(39.8)$ \\
\hline Blood pressure screening & $22(23.7)$ \\
\hline Breastfeeding counseling & $30(32.3)$ \\
\hline Cholesterol screening & $40(43)$ \\
\hline Depression screening & $27(29)$ \\
\hline Diabetes screening & $39(41.9)$ \\
\hline Fall prevention in older adults & $39(41.9)$ \\
\hline Counseling on folic acid supplementation to prevent birth defects & $34(36.6)$ \\
\hline Healthy diet and/or physical activity counseling & $31(33.3)$ \\
\hline Hepatitis C screening & $27(29)$ \\
\hline HIV screening & $24(25.8)$ \\
\hline Intimate partner violence screening & $22(23.7)$ \\
\hline Obesity screening and management & $34(36.6)$ \\
\hline Osteoporosis screening & $41(44.1)$ \\
\hline Sexually transmitted infection behavioral counseling & $31(33.3)$ \\
\hline Skin cancer behavior counseling & $36(38.7)$ \\
\hline Tobacco use screening or counseling & $38(40.9)$ \\
\hline Tuberculosis screening & $26(28)$ \\
\hline
\end{tabular}

* Note: Respondents could select $>1$ service 
Table 5. Barriers to providing clinical preventive services reported by community pharmacists $(n=93)$

\begin{tabular}{|l|c|}
\hline Barrier & $\mathbf{n}(\%)$ \\
\hline Lack of time & $74(79.6)$ \\
\hline Lack of staff & $61(65.6)$ \\
\hline Lack of reimbursement & $52(55.9)$ \\
\hline Don't feel knowledgeable/don't have skills to provide & $48(51.6)$ \\
\hline Lack of space & $47(50.5)$ \\
\hline Lack of required resources (CLIA waiver, supplies, etc) & $35(37.6)$ \\
\hline Patient not receptive & $34(36.6)$ \\
\hline Other healthcare professionals likely providing service & $33(35.5)$ \\
\hline Not needed in patient population & $4(4.3)$ \\
\hline
\end{tabular}

* Note: Respondents could select $>1$ barrier

Table 6. Respondents $(n=93)$ wanting more information about clinical preventive services

\begin{tabular}{|l|l|}
\hline \multicolumn{1}{|c|}{ Clinical Preventive Service } & \multicolumn{1}{|c|}{$\mathbf{n ~ ( \% )}$} \\
\hline Alcohol misuse screening and counseling & $27(29)$ \\
\hline Blood pressure screening & $36(38.7)$ \\
\hline Breastfeeding counseling & $19(20.4)$ \\
\hline Cholesterol screening & $33(35.5)$ \\
\hline Depression screening & $28(30.1)$ \\
\hline Diabetes screening & $31(33.3)$ \\
\hline Fall prevention in older adults & $18(19.4)$ \\
\hline Counseling on folic acid supplementation to prevent birth defects & $19(20.4)$ \\
\hline Healthy diet and/or physical activity counseling & $38(40.9)$ \\
\hline Hepatitis C screening & $15(16.1)$ \\
\hline HIV screening & $19(20.4)$ \\
\hline Intimate partner violence screening & $12(12.9)$ \\
\hline Obesity screening and management & $25(26.9)$ \\
\hline Osteoporosis screening & $23(24.7)$ \\
\hline Sexually transmitted infection behavioral counseling & $18(19.4)$ \\
\hline Skin cancer behavior counseling & $27(29)$ \\
\hline Tobacco use screening and counseling & $33(35.5)$ \\
\hline Tuberculosis screening & $13(14)$ \\
\hline
\end{tabular}

* Note: Respondents could select $>1$ service 